\title{
Picroside I inhibits asthma phenotypes by regulating T- bet/GATA-3 ratio and Th1/Th2 balance in a murine model of asthma
}

\author{
Sen Zhang ${ }^{1 *}$, Yuemei Lu', Jinhong Zheng ${ }^{2}$, Hua Qin ${ }^{3}$, Xiaoling Qiu ${ }^{4}$, Haile \\ Huang $^{5}$, Guangzhou Mo', Songrong Liang ${ }^{1}$, Yaowei Zhang ${ }^{6}$ \\ ${ }^{1}$ Department of respiration, Luoding People's Hospital, Luoding, Yunfu 527200, ${ }^{2}$ Department of Chemistry, Shantou University \\ Medical College, Shantou 515041, ${ }^{3}$ State Key Laboratory of Respiratory Disease, The First Affiliated Hospital of Guangzhou \\ Medical University, Guangzhou 510120, ${ }^{4}$ Department of Respiration, The First Affiliated Hospital of Shantou University, \\ Shantou, ${ }^{5}$ Department of Respiration, Zhuhai People's Hospital, Zhuhai, Guangdong 519000, ${ }^{6}$ Department of Pathology, The \\ Second Affiliated Hospital of Shantou University, Shantou, China
}

*For correspondence: Email: senzhang58@hotmail.com; Tel/Fax: 0086-0766-3822324

\begin{abstract}
Purpose: To examine the anti-asthmatic activity of picroside I in murine asthma model, and to elucidate the mechanism(s) involved.

Methods: The study involved systematic sensitization of acclimatized BALB/c mice with ovalbumin (OVA), and subsequent exposure to aerosol allergens. The effect of picroside I on associated IgE formation was determined. All assays were performed using standard protocols. Protein expression was assessed using western blotting.

Results: Picroside I inhibited allergic airway inflammation, AHR, and the production of OVA-associated IgE and Th2 cytokines. Moreover, it altered the T-bet/GATA3 ratio by suppressing the phosphorylation of STAT6 in a dose-dependent manner.

Conclusion: These results indicate that the anti-asthmatic effect of picroside I occurs via a mechanism involving inhibition of Th2 cytokines by suppression of the expressions of pSTAT6 and GATA-3, and upregulation of the expression of T-bet. Thus, picroside I is a promising agent for the management of asthma.
\end{abstract}

Keywords: Picroside, Asthma, Allergic response, IgE, GATA-3, pSTAT6

\begin{abstract}
This is an Open Access article that uses a funding model which does not charge readers or their institutions for access and distributed under the terms of the Creative Commons Attribution License (http://creativecommons.org/licenses/by/4.0) and the Budapest Open Access Initiative (http://www.budapestopenaccessinitiative.org/read), which permit unrestricted use, distribution, and reproduction in any medium, provided the original work is properly credited.
\end{abstract}

Tropical Journal of Pharmaceutical Research is indexed by Science Citation Index (SciSearch), Scopus, International Pharmaceutical Abstract, Chemical Abstracts, Embase, Index Copernicus, EBSCO, African Index Medicus, JournalSeek, Journal Citation Reports/Science Edition, Directory of Open Access Journals (DOAJ), African Journal Online, Bioline International, Open-J-Gate and Pharmacy Abstracts

\section{INTRODUCTION}

Asthma is considered one of the main chronic inflammatory airway diseases. It impacts over three hundred million people the world over, and is expected to affect another hundred million by 2025 [1]. The frequency of allergic asthma has elevated considerably in the recent past, thereby posing a serious health problem [2]. Allergic asthma is primarily caused by a number of allergens which include, but are not limited to house dust, foods, and drugs. The major symptoms of asthma are wheezing, breathlessness and cough [3]. These symptoms 
result from bronchoconstriction and thickening of bronchial mucosa due to inflammation of the eosinophilic airway, remodelling of the airways, and production of larger-than-normal amounts of mucus. Indeed, allergic asthma is allied with inflammation of the airways and disproportionate production of mucus [4].

In allergic asthma, the inflammation of the airways is regulated by a multifaceted mechanism [4,5]. During an asthmatic attack, the allergens processed by antigen-presenting cells trigger the initiation of Th2 cells and release of various cytokines. These cytokines intensify the allergic response by enhancing inflammatory cell infiltration into the airways, and by initiating disproportionate formation of mucus [6].

The differentiation of Th2 and regulation of the transcription of Th2 cytokines involves GATA-3. In this process, the initiation of signal transducer and transcription-6 (STAT6) activator via interleukin-4 signal transduction causes dimerization and STAT6 phosphorylation to PSTAT6 which, in the nucleus, triggers the expression of GATA-binding protein-3 (GATA3), leading to Th2 cell differentiation [5].

Picrorhiza kurroa is a highly imperilled, medicinal herb found only in the North Western Alpine Himalayas (altitude, $2800-4800 \mathrm{~m}$ ) [7]. It is the source of picroside 1 . Studies have shown that picrosides exhibit diverse medicinal effects which include, but are not limited to hepatoprotective, anti-inflammatory, and anti-carcinogenic effects $[5,6]$. In the present investigation, the impact of picroside I on inflammation of airway in asthma model was evaluated.

\section{EXPERIMENTAL}

\section{Animals}

Five-week old BALB/c female mice were procured from Shantou University Medical College, and were kept under controlled conditions. The animals were given standard pellet diet ad libitum. Prior to commencement of the study, the mice were acclimatised to laboratory conditions for seven days. The study was approved by the animal ethics committee of Luoding People's Hospital, Luoding, (Approval no. C7A547LH/2017) and all the procedures were carried out as per standard international guidelines [8].

\section{Animal grouping and treatment}

The mice were randomly grouped into 6 different groups. Mice in group 1 (sham, normal control) received phosphate-buffered saline (PBS, vehicle) only. Group 2 mice were OVA control (OVA-sensitized and OVA-challenged (OVA/OVA + vehicle); while mice in group 3 were OVAsensitized, OVA-challenged, and given $0.7 \mathrm{mg} / \mathrm{kg}$ dexamethasone (OVA/OVA/DEXA). Groups 4 - 6 mice OVA-sensitized, OVA-challenged, and given picroside 1 at concentrations of $0.2,2.0$ and $20 \mathrm{mg} / \mathrm{kg}$ (OVA/OVA/picroside 1-treated). Dexamethasone were given orally, once daily from day 20 to day 32 , with PBS as vehicle. The procedure used for inducing allergic asthma is summarised in Figure 1.

\section{Sensitization, airway OVA challenge and treatments}

For sensitization of the mice, $40 \mu \mathrm{g}$ of OVA plus $2.6 \mathrm{mg}$ of $\mathrm{Al}(\mathrm{OH})_{3}$ in PBS $(200 \mu \mathrm{L})$ were given intraperitoneally on days 0 and 7 . The mice were thereafter administered $5 \%$ OVA in PBS from days 21 to 32 . Dexamethasone and picroside were given once per day from day $19^{\text {th }}$ to $25^{\text {th }}$. Some mice were sacrificed on $24^{\text {th }}$ day, and broncho alveolar lavage was carried out to assess lung eosinophilia.

\section{Measurement of airway hyper- responsiveness (AHR) and collection of BALF}

The measurement of AHR was carried out as
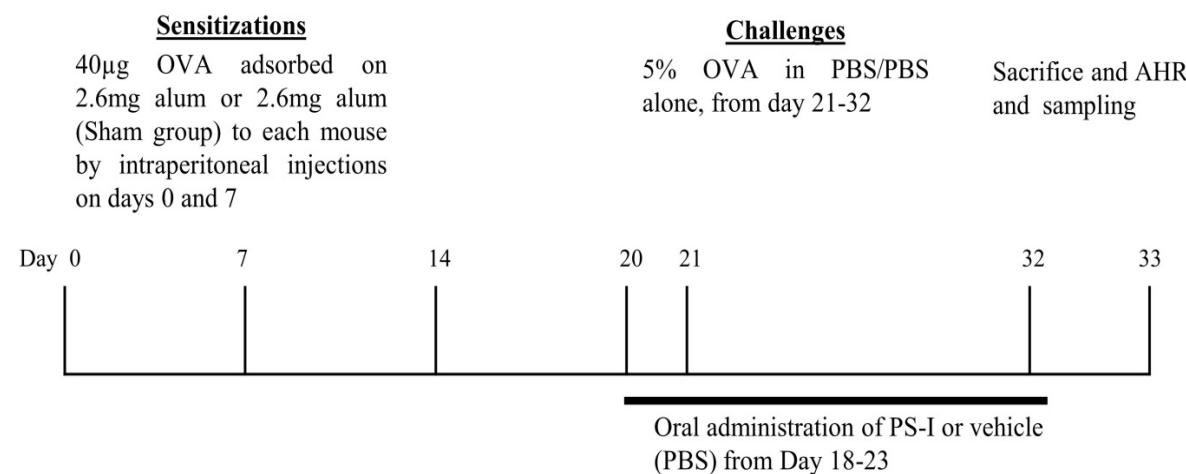

Figure 1: Procedure used for triggering allergic asthma in the mice 
described previously [9]. On day 33 , the mice were sacrificed under ether anaesthesia, and their BALF portions were harvested for differential cell counting and estimation of cytokine levels. The whole procedure was carried out as described earlier [9].

\section{Evaluation of cytokines and OVA-specific Immunoglobulin E (IgE)}

Serum cytokine (IL-5, IL-4 IL-13 and IFN- Y) were estimated using ELISA ( $R$ \& $D$ Systems) kits in line with the manufacturer's guidelines. The assay of OVA-specific $\operatorname{lgE}$, was done using a microtiter plate as described previously in literature $[9,10]$.

\section{Western blotting analysis for protein expression}

The lungs were homogenized in buffer and their protein concentrations were determined with Bradford method. Protein expression was measured using western blotting as described previously [2].

\section{Histological examination}

After the collection of BALF from the lungs, the left lung was carefully isolated and subjected to fixation in neutral buffered formalin (10\%) for 24 h. The specimens were subjected to dehydration and subsequently paraffin-embedded. Thereafter, $5-\mu \mathrm{m}$ sections of the fixed and embedded tissues were subjected to $H$ \& $E$ staining. Histological analysis was carried out as described previously [8].

\section{Statistical analysis}

Data are shown as mean \pm SEM. Statistical analysis was done using Students $t$-test with GraphPad prism 7 software. Values of $p<0.05$ were considered as indicator of significant difference.

\section{RESULTS}

\section{Picroside I reduced AHR in experimental asthma model}

The airway resistance developed by treatment with methacholine at concentrations ranging from 0 to $16 \mathrm{mg} / \mathrm{ml}$ was considerably enhanced in the OVA group. Assessment of the picroside I on AHR revealed no significant differences in the baseline airway resistance among the six groups. In contrast, there was significant decreases in airway resistance in the control, DEXA and picroside I (2 and $20 \mathrm{mg} / \mathrm{kg}$ )-treated groups (Figure 2). However, the decline in airway resistance in the $0.2 \mathrm{mg} / \mathrm{kg}$ was not significant.

\section{Picroside I influenced the release of Th1 and Th2 cytokines}

The Th2 cytokines IL-4 (Figure 3A), IL-5 (Figure 3B) and IL-13 (Figure 3C) were measured in mice sera. Mice administered picroside $\mathrm{I}$ at concentrations of $0.2,2$ and $20 \mathrm{mg} / \mathrm{kg}$ exhibited no remarkable changes in these cytokines relative to control group. However, picroside I enhanced the secretion of IFN-y (Figure 3D), a Th1 cytokine, dose-dependently, indicative of its impact on T cell differentiation.

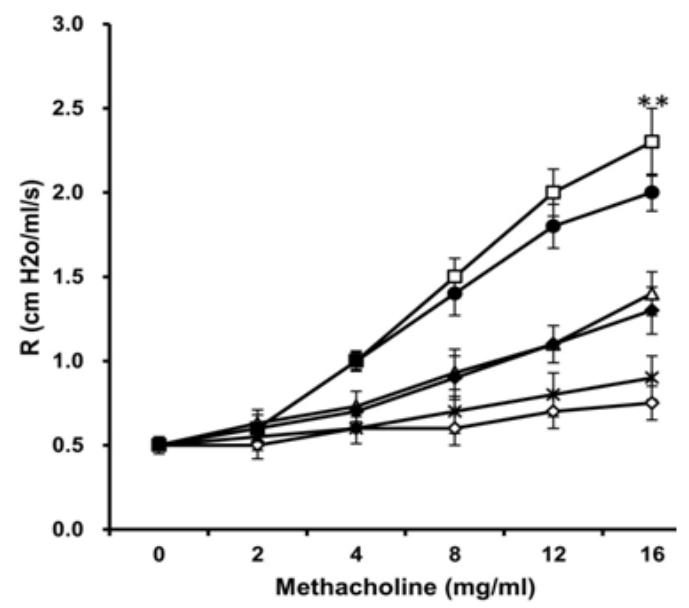

Figure 2: Estimation of airway hyper-responsiveness (AHR). Picroside I treatment caused reductions of airway hyper-responsiveness in mice. Data are shown as mean $\pm \mathrm{SEM} ;{ }^{*} p<0.05 ;{ }^{* *} p<0.01$, compared with sham/PBS group. $(\nabla=$ Control, $\square=$ OVA control, $\Delta=$ DEXA (0.7 mg/kg), $\bullet=$ PS $-1(0.2 \mathrm{mg} / \mathrm{kg}), \bullet=$ PS $-1(2$ $\mathrm{mg} / \mathrm{kg}), \mathbf{\square}=\mathrm{PS}-1(20 \mathrm{mg} / \mathrm{kg})$

\section{Picroside I reduced OVA-associated IgE levels}

Picroside 1 administration (0.2, 2 and $20 \mathrm{mg} / \mathrm{kg}$ ) did not resulted in any marked alterations in the OVA-associated IgE levels, when compared to the control group (Figure 4).

\section{Picroside I attenuated airway inflammation}

Mice BALF was analysed for inflammatory cells. Only a few inflammatory cells were observed in the control group. In contrast, there were marked increases in the population of inflammatory cells in mice sensitized and challenged with OVA. The impact of picroside I on allergen-triggered inflammatory cell penetration was determined in mice administered 3 varied concentrations of picroside I. As depicted in Table 1, picroside I at 

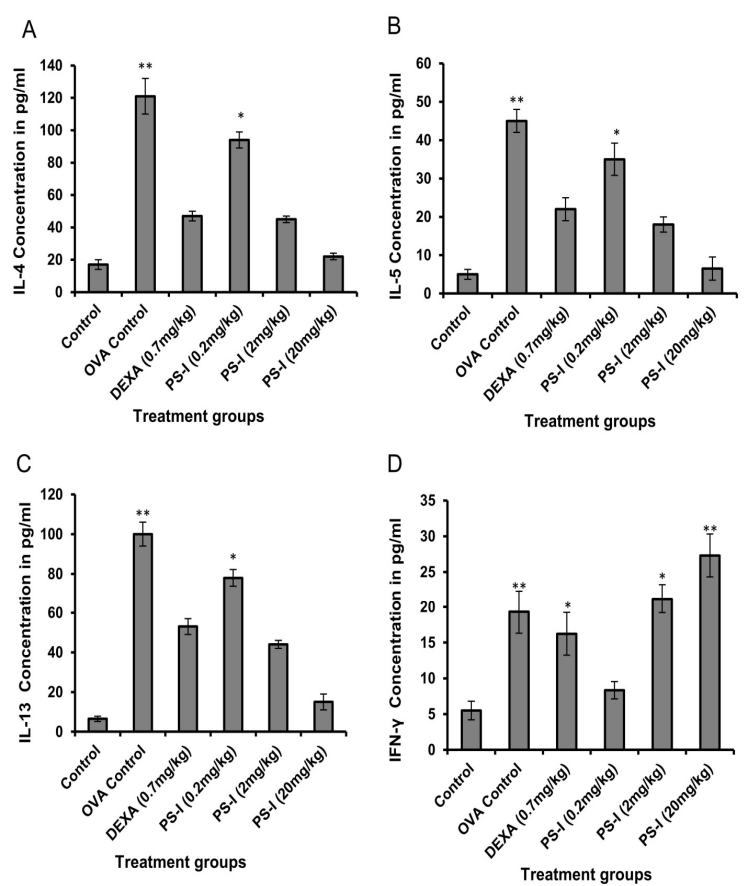

Figure 3: Effect of picroside I on Th1 and Th2 release: IL-4 (A), IL-5 (B) IL-13 (C), and IFN-Y (D) IL-4, IL-5, IL13 and IFN-y levels in BAL fluid. Data are shown as mean \pm SEM; ${ }^{*} p<0.05,{ }^{* *} p<0.01$, vs sham/PBS

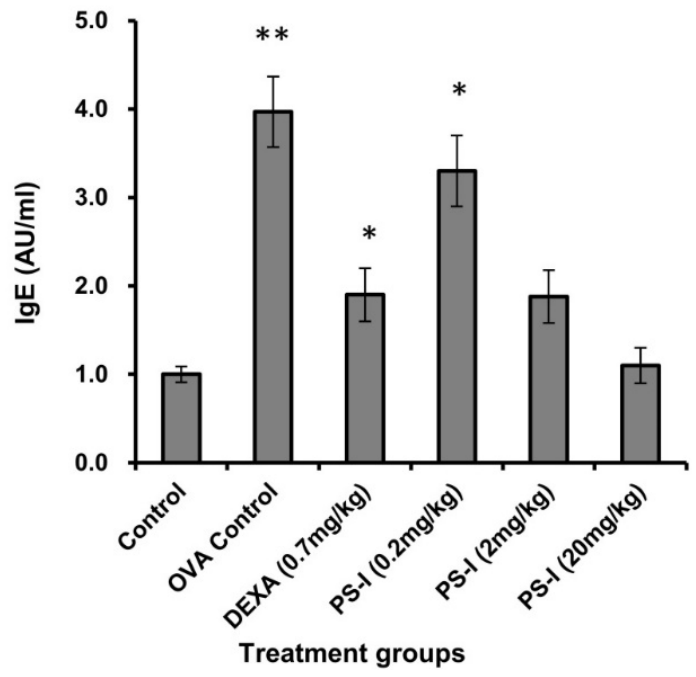

arbitrary units. Data are shown as mean \pm SEM; ${ }^{*} p<$ 0.05 , compared with sham/PBS

$0.2,2$ and $20 \mathrm{mg} / \mathrm{kg}$ inhibited allergen-triggered inflammatory cell infiltration. Nonetheless, in the group given $0.2 \mathrm{mg} / \mathrm{kg}$, the infiltration of inflammatory cells was profound, when compared to other picroside l-treated groups. The anti-inflammatory effect of picroside I was evident from the histological examination of $\mathrm{H}$ \& $E$ stained sections of lung (Figure 4A). A remarkable increase in inflammatory cells in the airway was found in OVA-adminstrated mice, when compared with PBS-treated control mice. However, there were remarkable reductions in infiltration of inflammatory cells in mice administered different concentrations of picroside I.

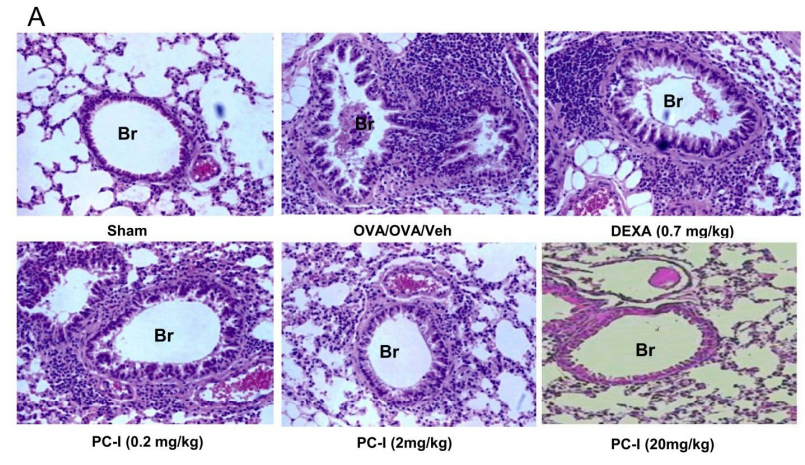

B

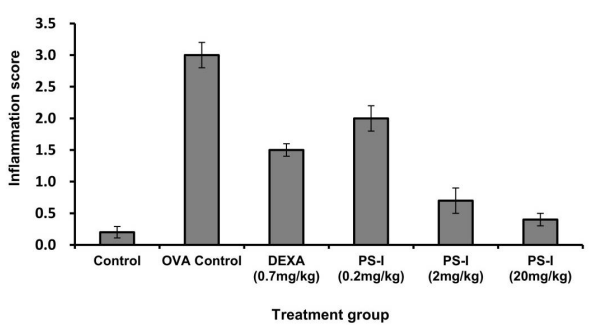

Figure 5: (A) Picroside I administration considerably decreased airway infiltration of inflammatory cells. (B) Quantitative determination of inflammation using inflammation score

Figure 4: Effect of picroside I on the release of OVAspecific $\lg$ E, as evaluated by ELISA and presented as

Table 1: Effect of picroside I on total cell count and differential cell count

\begin{tabular}{|c|c|c|c|c|c|}
\hline \multirow{2}{*}{$\begin{array}{l}\text { TCC } \\
\left(\times 10^{4} / \mathrm{ml}\right) \\
\end{array}$} & & \multicolumn{4}{|c|}{ Differential count (\%) } \\
\hline & & Macro & Mono & Eosino & Neutro \\
\hline SHAM/PBS/VEH & $3.1 \pm 1.4$ & $37.5 \pm 4.4$ & $43.1 \pm 4.2$ & $1 \pm 0.12$ & $2 \pm 0.3$ \\
\hline OVA/OVA/VEH & $55.2 \pm 4.3^{* *}$ & $10.6 \pm 3.1^{*}$ & $11.4 \pm 2.3^{*}$ & $57.1 \pm 3.2^{* *}$ & $23.2 \pm 3.4^{*}$ \\
\hline PS-I-0.2mg/kg & $37.2 \pm 9.4^{\star}$ & $15.2 \pm 3.2^{*}$ & $18.5 \pm 3.5$ & $28.5 \pm 4.1^{*}$ & $15.2 \pm 2.2$ \\
\hline PS-I -2mg/kg & $12.3 \pm 2.2$ & $24.5 \pm 4.5$ & $22.1 \pm 4.3$ & $8.4 \pm 3.1$ & $10.4 \pm 1.4$ \\
\hline PS-I -20mg/kg & $8.5 \pm 3.6$ & $40.1 \pm 4.6$ & $40.2 \pm 4.3$ & $3.2 \pm 0.2$ & $2.6 \pm 0.4$ \\
\hline OVA/OVA/DEXA & $10.4 \pm 2$ & $24.4 \pm 5.2$ & $37.2 \pm 2.4$ & $10.4 \pm 5$ & $10.3 \pm 2.2$ \\
\hline
\end{tabular}

Data are shown as mean \pm SEM. ${ }^{*} p<0.05,{ }^{\star *} p<0.01$, compared with sham/PBS 


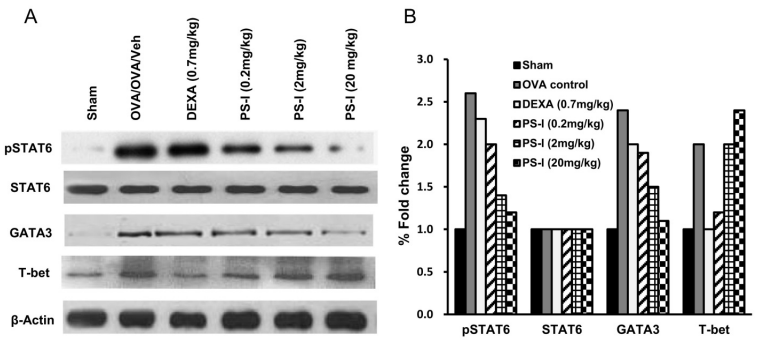

Figure 6: (A) Effect of picroside 1 on pSTAT6, GATA3 and T-bet expressions, as determined using western blot; (B) densitometric analysis of pSTAT6, STAT6, GATA3 and T-bet expressions

\section{Picroside I modulated pSTAT6, GATA-3 and $T$-bet expressions in lung tissue}

The expressions of pSTAT6, GATA-3 and T-bet in lung tissue homogenates were determined in control, OVA control, DEXA-administrated, and picroside I-treated mice. There were no expressions of pSTAT6, GATA-3 and T-bet in control mice. However, the expressions of PSTAT6 and GATA-3 were highly upregulated in OVA control mice. In picroside I-treated group, the expressions of pSTAT6 and GATA-3 were downregulated, indicating an inhibitory effect on Th2 cell differentiation (Figure 6). The picroside 1 -induced decreases were concentrationdependent, but there was no detectable expression in the $20 \mathrm{mg} / \mathrm{kg}$ picroside administrated group. The dose-dependent modulation of T-bet expression by picroside I further confirmed that the decrease in Th2 cytokine release was due to modulation of GATA3 by picroside I.

\section{DISCUSSION}

The spotlight in the development of drugs for asthma currently is either on improving the efficiency of available drugs or searching for novel compounds that can target the Th2-specific transcription factors [11]. The latter is based on the central and principal function of Th2 cytokines in escalating inflammation of airway and the transcription factor genes that control their production. However, this approach requires inhibition of the monoclonal antibodies and Th2cell transcription factors $[3,12]$.

The transcription factor family GATA which includes 6 members, harbours a prevalent DNA binding domain that is evolutionarily preserved across vertebrates. With respect to the immune system, GATA3 is the imperative among all members of GATA family [13,14-16]. This transcription factor is regarded as the main controller of Th2 cell differentiation. It is a downstream gene expressed after IL-4-induced
STAT6 phosphorylation [17,18]. Coordinated control of Th2 cytokines is vital for an allergic response such as asthma. The cytokines have a major function in AHR advancement, IgE generation, eosinophills of airway, and high mucus secretion, all of which are the main features of allergic asthma [12,19]. Furthermore, T-bet transcription factor along with GATA-3 maintains a suitable Th1/Th2 cell ratio in the body under normal physiologic conditions. An imbalance in this ratio may result in a disease condition. The two transcription factors control the expression of each other. An increase in the expression of one subsequently suppresses the expression of the other. Therefore, T-bet/GATA-3 ratio is used to investigate immune equilibrium in the Th1/Th2 responses in asthma [9]. Enhanced expression of T-bet transcription factor shifts the equilibrium to Th1, and causes increased release of Th1 cytokines [3,20].

In the current investigation, standard OVAtriggered murine model of asthma was used to study the anti-asthmatic activity of picroside I. It was observed that picroside I abridged the employment of inflammatory cells to the microenvironment of the lungs. In this model, picroside I caused decrease in the methacholinetriggered AHR in OVA-immunized asthmatic mice. In addition, it caused reduction in the release of Th2 cytokines by Th2 cells and production of OVA-specific IgE in a concentration-dependent fashion. Histology results showed absence of inflammation in the lung sections around the bronchioles in the control group. However, in the OVA control group, maximum inflammation was observed. Picroside I reduced the inflammation significantly at its higher dose. It also downregulated pSTAT6 and GATA3 expressions. Reduction in the expression of these two transcription factors is related to the reduction in the release of cytokines, IgE production and airway eosinophilia or airway inflammation. In addition, picroside I treatment dose-dependently increased the serum levels of IFN- $\gamma$, a Th1 cytokine, and the expression of $\mathrm{T}$-bet in the lung dose dependently.

T-bet expression varied indirectly with that of GATA3 expression, i.e., for a decrease in GATA3 expression, there was a corresponding increase in T-bet expression. Therefore, it can be postulated that picroside I attenuates asthma features in a mouse model of asthma by altering T-bet/GATA-3 ratio which reflects alterations in the Th1/Th2 balance. Furthermore, picroside I suppressed STAT6 phosphorylation which resulted in decreased GATA3 expression and 
increased expression of $\mathrm{T}$-bet at increasing doses of picroside I.

\section{CONCLUSION}

The findings of this study show that picroside I suppresses asthma phenotypes by altering Tbet/GATA-3 ratio, thereby altering Th1/Th2 equilibrium in a murine model of asthma. Therefore, picroside I is a potential therapeutic agent for the management of asthma via amelioration of allergic responses.

\section{DECLARATIONS}

\section{Conflict of Interest}

No conflict of interest associated with this work.

\section{Contribution of Authors}

The authors declare that this work was done by the authors named in this article and all liabilities pertaining to claims relating to the content of this article will be borne by them. Sen Zhang, Yuemei Lu, Jinhong Zheng, Hua Qin, Xiaoling Qiu performed all the experiments. Haile Huang, Guangzhou Mo, Songrong Liang, Yaowei Zhang carried out literature survey and compiled the data.

\section{REFERENCES}

1. Masoli M, Fabian $D$, Holt $S$, Beasley $R$. The global burden of asthma: executive summary of the GINA Dissemination Committee report. Allergy 2004; 59: 469478.

2. Liu $L Y$, Coe CL, Swenson CA, Kelly EA, Kita H, Busse $W W$. School examinations enhance airway inflammation to antigen challenge. Am J Respir Crit Care Med 2002; 165: 1062-1067.

3. Holgate ST, Polosa R. Treatment strategies for allergy and asthma. Nat Rev Immunol 2008 8: 218-230.

4. Lee MY, Lee JA, Seo CS, Ha H, Lee NH, Shin HK. Protective effects of menthe haplocalyx ethanol extract $(\mathrm{MH})$ in a mouse model of allergic asthma. Phytother Res 2011; 25: 863-869.

5. Ricciardolo FL, Sterk PJ, Gaston B, Folkerts G. Nitric oxide in health and disease of the respiratory system. Physiol Rev 2004; 84: 731-765.

6. Bloemen K, Verstraelen S, Van Den Heuvel R, Witters $H$, Nelissen I, Schoeters $G$. The allergic cascade: review of the most important molecules in the asthmatic lung. Immunol Lett 2007; 113: 6-18.

7. Yuk JE, Lee MY, Kwon OK, Cai XF, Jang $H Y$, Oh SR, Lee HK, Ahn KS. Effects of astilbic acid on airway hyperresponsiveness and inflammation in a mouse model of allergic asthma. Int Immunopharmacol 2011; 11: 266-273.

8. Kilkenny C, Browne WJ, Cuthill IC, Emerson M, Altman $D G$. Improving bioscience research reporting: the ARRIVE guidelines for reporting animal research. PLOS boil 2010; 8: e1000412.

9. Zhou W, Nie X. Afzelin attenuates asthma phenotypes by downregulation of GATA3 in a murine model of asthma. Mol Med Rep 2015; 12: 71-76.

10. Bukhari SI, Pattnaik B, Rayees S, Kaul S, Dhar MK. Safranal of Crocus sativus $L$. inhibits inducible nitric oxide synthase and attenuates asthma in a mouse model of asthma. Phytother Res 2015; 29: 617-627.

11. Caramori G, Groneberg D, Ito K, Casolari P, Adcock IM, Papi A. New drugs targeting Th2 lymphocytes in asthma. J Occup Med Toxicol 2008; 3: S6.

12. Rayees S, Mabalirajan U, Bhat WW, Rasool S, Rather RA, Panda L, Satti NK, Lattoo SK, Ghosh B, Singh G. Therapeutic effects of $R 8$, a semi-synthetic analogue of Vasicine, on murine model of allergic airway inflammation via STAT6 inhibition. Int Immunopharmacol. 2015; 26: 246-256.

13. Cheng $Y$, Zhang J, Hou W, Wang D, Li F, Zhang Y, Yuan $F$. Immunoregulatory effects of sinomenine on the $T$ bet/GATA-3 ratio and Th1/Th2 cytokine balance in the treatment of mesangial proliferative nephritis. Int Immunopharmacol 2009; 9: 894-899.

14. Ho IC, Vorhees $P$, Marin N, Oakley BK, Tsai SF. Human GATA-3: a lineage-restricted transcription factor that regulates the expression of the $T$ cell receptor alpha gene. EMBO J 1991; 10:1187-1192.

15. Oosterwegel M, Timmerman J, Leiden J, Clevers $H$. Expression of GATA-3 during lymphocyte differentiation and mouse embryogenesis. Dev Immunol. 1992; 31: 111.

16. Samson SI, Richard O, Tavian M, Ranson $T$, Vosshenrich CA, et al. GATA-3 promotes maturation, IFN-gamma production, and liver-specific homing of NK cells. Immunity. 2003; 19: 701-711.

17. Ouyang W, Ranganath SH, Weindel $K$, Bhattacharya $D$, Murphy $T L$, et al. Inhibition of Th1 development mediated by GATA-3 through an IL-4-independent mechanism. Immunity 1998; 95: 745-755.

18. Rayees S, Malik F, Bukhari SI, Singh G. Linking GATA-3 and interleukin-13: implications in asthma. Inflamm Res 2014; 63: 255-265.

19. O'Garra A. Cytokines induce the development of functionally heterogeneous $T$ helper cell subsets. Immunity 1998; 8: 275-283.

20. Mabalirajan U, Dinda AK, Kumar S, Roshan R, Gupta $P$, Sharma SK, Ghosh B. Mitochondrial structural changes and dysfunction are associated with experimental allergic asthma. J Immunol 2008; 181: 3540-3548. 